\title{
EDITORIAL
}

\section{MILLENNIUM DEVELOPMENT GOAL 5: SITUATION ANALYSIS}

At the Millennium Summit in September 2000, world leaders adopted the United Nations Millennium Declaration, which included attainment of the eight Millennium Development Goals (MDGs) by 2015 (Table 1) (1). The first seven MDGs are aimed at reducing poverty and promoting human development while the eighth MDG recognises the essence of global partnership in achieving the first seven. The three MDGs directly related to health (MDGs 4-6) are interdependent so concerted efforts are needed to achieve them.

\section{Table 1}

The Millennium Development Goals

1. Reduce extreme poverty and hunger by half between 1990 and 2015

2. Achieve universal primary education

3. Promote gender equality and empower women

4. Reduce child mortality by $75 \%$ between 1990 and 2015

5. Reduce maternal mortality by three-quarters between 1990 and 2015

6. Combat HIV/AIDS, malaria, and other diseases

7. Ensure environmental sustainability

8. Develop a global partnership for development

The fifth MDG is to reduce maternal mortality ratio by $75 \%$ between 1990 and 2015. The WHO/ UNICEF/UNFPA global model estimates of maternal mortality ratio for the years 1990, 1995 and 2000 were 430, 400, and 400 maternal deaths per 100,000 live births respectively (2-4). Further, maternal mortality remains the health indicator with the widest disparity between developed and developing countries. With the exception of Afghanistan, all countries with maternal mortality ratio over 1000 maternal deaths per 100,000 live births in the year 2000 were in sub-Saharan Africa (4). These estimates indicate that unless urgent steps are taken in the next decade it is unlikely the fifth MDG will be attained especially in sub-Saharan Africa. The two main lingering issues are whether we will be able to ascertain the attainment of the fifth MDG in the year 2015 and what evidence-based measures are needed to curb the prevailing high maternal mortality in developing countries particularly in sub-Saharan Africa.

In sub-Saharan Africa, where data on maternal deaths are notably incomplete and inaccurate, maternal mortality estimates have to be interpreted with caution. Most of WHO/UNICEF/UNFPA model maternal mortality estimates for sub-Saharan Africa are at variance with government estimates. For example, the Government of Kenya hopes to reduce its maternal mortality ratio from 590 maternal deaths per 100,000 live births in 1998 to 170 maternal deaths per 100,000 live births by 2010 while the WHO/UNICEF/UNFPA estimates for Kenya in years 1995 and 2000 are 1,300 and 1,000 maternal deaths per 100,000 live births respectively $(4,5)$. With the difficulty in measuring maternal mortality, monitoring trends in maternal mortality will be challenging and certainly, the attainment of the fifth MDG in 2015 will be a subject of major debate.

In sub-Saharan Africa, facility-based maternal mortality figures are under-estimates given that majority of women deliver at home without the assistance of skilled attendants (6). Further, health facilities estimates do not typically relate to a defined geographical area so it is not easy to interpret trends over time. The Kenyatta National Hospital maternal mortality figures do not give any indication of the maternal mortality in Nairobi (7). Considering that it is the main referral hospital, one would expect the maternal mortality ratio to be higher than in other health facilities in Nairobi since more life-threatening complications end up there. On the other hand, one could surmise that the maternal mortality would be lower since it has more qualified health professionals than most hospitals in Nairobi. Demographic surveillance systems, which record all births and deaths in an area, provide more accurate maternal mortality figures but they typically cover a district or sub-district and are more costly. Moreover, national survey estimates, which are recommended to be undertaken once every 10 years, are imprecise and do not provide information on the delays and barriers to the utilisation of emergency obstetric care (8). There is therefore the need to have complete and accurate vital registration systems to complement health facility records in providing timely information to policy-makers. Indeed, countries such as Sweden that demonstrated reductions in maternal mortality in 1751-1900 and more recently, Malaysia and Sri Lanka relied on adequate vital registration systems $(9,10)$. Sub-Saharan African countries have to start investing in vital registration systems to provide data for decision-making not only on maternal health but also on other aspects of health.

Of the five main causes of maternal mortality in developing countries (haemorrhage, sepsis, obstructed labour, pregnancy induced hypertension, and abortion complications), abortion-related deaths deserve special attention since they remain a major direct cause of maternal death in sub-Saharan Africa. The World Health Organisation abortion estimates in 2000 indicate that Eastern Africa had the highest mortality due to unsafe abortion in the world (140 unsafe abortion deaths per 100,000 live births) (11). Oyieke et al 
reported that post-abortion infection alone accounted for a quarter of all maternal deaths in Kenyatta National Hospital in the period 1995-1999. This presupposes that most women with post-abortion infection arrive at the hospital too late to be saved. Owing to the sensitive nature of abortion, it has become a back burner issue in the international discourse on the prevailing high maternal mortality in developing countries. While abortion is legally restricted in several countries including Kenya, post-abortion services including family planning should be more accessible to women. This calls for rapid expansion of all services allowed within prevailing legal framewoks, while conducting open and honest debate on the laws governing abortion to dilate certain provisions so that emergency services are accessible to all women with abortion related problems, irrespective of their socioeconomic status. Romania provides a natural experiment for the correlates between abortion law and maternal mortality. Prior to 1966 when abortion was legal, maternal mortality was about 80 maternal deaths per 100,000 live births; this increased to a high of 170 maternal deaths per 100,000 live births in the period 1966-1989 when abortion was illegal; and plummeted to about 50 maternal deaths per 100,000 live births in 1996 when it was declared legal again in 1989 (12).

The major causes of maternal mortality can be prevented if women have access to good quality emergency obstetric services (13). Demographic and Health Surveys (DHS) in sub-Saharan Africa indicate that majority of women go for antenatal care but deliver at home; yet it is during delivery and the immediate postpartum that most maternal deaths occur. Women who seek antenatal care with skilled birth attendants should be encouraged to deliver with the assistance of skilled attendants. The dilemma is whether the health system can support all women, should they decide to deliver with skilled attendants or at health facilities. The flight of health professionals to developed countries has worsened the situation.

With the paucity of skilled birth attendants in subSaharan Africa, there is a wide disparity in their use between the rich urban and the poor rural populations. Table 2 shows the percentage of births with skilled attendants in selected recent DHS. In all these countries, the percentages in the rural populations were much lower than the urban populations with the urban-rural difference ranging from a low of $13.6 \%$ in Benin to a high of $57.2 \%$ in Burkina Faso. It is clear that urban populations in many sub-Saharan African countries (including Nairobi) have achieved the 1999 special session of the United Nations General Assembly (ICPD+5) goal of $80 \%$ of skilled attendants by 2005 while the rural folks are far behind (13). Efforts to improve national percentages of births with skilled attendants must focus on the rural areas and the urban poor. Nevertheless, skilled birth attendants without a functioning health delivery system will not make a dent in maternal mortality.

Table 2

Percentage of births with skilled attendants (rural-urban difference) by country and year: three years preceding recent demographic and health surveys in sub-Saharan Africa

Percentage of births with skilled attendants

\begin{tabular}{lccccc}
\hline Country & Year & Total & Urban & Rural $\begin{array}{c}\text { Urban-Rural } \\
\text { difference }\end{array}$ \\
\hline Benin & 2001 & 74.7 & 84.1 & 70.5 & 13.6 \\
Burkina Faso & 2003 & 38.1 & 88.1 & 30.9 & 57.2 \\
Eritrea & 2002 & 30.2 & 68.3 & 11.5 & 56.8 \\
Ethiopia & 2000 & 5.6 & 35.6 & 2.3 & 33.3 \\
Gabon & 2000 & 86.5 & 93.3 & 68.6 & 24.7 \\
Ghana & 2003 & 46.5 & 79.8 & 29.6 & 50.2 \\
Guinea & 1999 & 35.8 & 77.1 & 21.8 & 55.3 \\
Kenya & 2003 & 41.6 & 72.2 & 34.5 & 37.7 \\
Madagascar & 2003 & 44.8 & 70.6 & 39.2 & 31.4 \\
Malawi & 2000 & 54.4 & 81.1 & 50.5 & 30.6 \\
Mali & 2001 & 40.4 & 81.7 & 27.4 & 54.3 \\
Mauritania & 2000 & 53.6 & 85.9 & 29.1 & 56.8 \\
Mozambique & 2003 & 49.1 & 82.2 & 35.6 & 46.6 \\
Namibia & 2000 & 75.6 & 93.9 & 66.2 & 27.7 \\
Nigeria & 2003 & 38.6 & 60.3 & 29.3 & 31.0 \\
Rwanda & 2000 & 25.4 & 64.8 & 18.2 & 46.6 \\
Tanzania & 1999 & 43.0 & 82.7 & 33.5 & 49.2 \\
Uganda & 2000 & 38.7 & 81.3 & 33.4 & 47.9 \\
Zambia & 2001 & 42.5 & 78.1 & 27.1 & 51.0 \\
Zimbabwe & 1999 & 72.8 & 90.0 & 64.3 & 25.7 \\
\hline
\end{tabular}

Source: Demographic and Health Surveys, Measure DHS+

This calls for the strengthening of emergency obstetric services. Majority of health facilities especially in the rural areas do not even meet the criteria for basic emergency obstetric care (administration of parenteral antibiotics, parenteral oxytocic drugs, and parenteral anticonvulsants for pre-eclampsia; manual removal of retained placenta; removal of retained products of conception; and assisted vaginal delivery) $(15,16)$. Further, the poor referral and communication systems especially in remote rural areas contribute to the low utilisation of the available emergency services.

Most governments in sub-Saharan Africa have not demonstrated the necessary commitment to follow through with their affirmation of the fifth MDG. Unless dramatic steps are taken to make emergency obstetric care accessible to all women, the fifth MDG will become another illusory international goal. Oyieke et al (7) give a sober reminder that African women continue to die in large numbers from very preventable causes such as post abortion complications, even within our very capital cities and in the more revered teaching and referrals centres such as the Kenyatta National 
Hospital. It should be a wake up call to all African obstetricians and midwives of conscience to push African governments to live up to their international and human rights obligations.

Some of the steps governments can take are as follows:

- $\quad$ Equip health facilities and train more midwives to carry out all six basic emergency obstetric procedures

- Train more auxiliary nurses to perform procedures such as the taking of vital signs, bedding and toileting so that midwives can focus on emergency obstetric care procedures.

- Strengthen the referral system so that women who deliver at home can quickly get to a health facility in the event of obstetric complications

- $\quad$ Strengthen the vital registration systems as well as health facility records to allow monitoring and evidence-based decision-making.

- $\quad$ Provide adequate port-abortion services including family planning to women with abortion complications.

S. L. Mills, MBChB, DrPH and K. O. Rogo, MD, PhD, The World Bank, 1818 H Street NW Washington, DC 20433

\section{REFERENCES}

1. United Nations Millennium Declaration. Fifty-fifth Session of the United Nations General Assembly New York, United Nations, 18 September 2000, General Assembly document, No. A/RES/55/2.

2. WHO and UNICEF. 1996. Revised 1990 Estimates of Maternal Mortality: A New Approach by WHO and UNICEF, World Health Organization, Geneva.

3. Hill, K., AbouZahr, C. and Wardlaw, T. Estimates of maternal mortality for 1995. Bull. World Health Org. 2001; 79: $182-193$.
4. AbouZahr, C. and Wardlaw, T. 2003. Maternal Mortality in 2000: Estimates Developed by WHO, UNICEF and UNFPA.

5. National Council for Population and Development (NCPD) (Kenya). 2000. National population policy for sustainable development. Sessional Paper No. 1. Nairobi: NCPD.

6. Skilled attendant at 2005 estimates. http://www.who.int/ reproductive-health/global_monitoring/ skilled_attendant_at_birth2005_estimates.pdf.

7. Oyieke, J.B.O., Obore, S. and Kigondu, C.S. Millenium development goal 5: a review of maternal mortality at the Kenyatta National Hospital, Nairobi. East Afr. Med. J. 2006; 83: 4-9.

8. Stanton, C., Abderrahim, N., and Hill, K. An assessment of DHS maternal mortality indicators. Studies in Family Planning. 2000; 31: 111-123.

9. Hogberg, U., Wall, S. and Brostrom, G. The impact of early medical technology on maternal mortality in late 19th century Sweden. Int. J. Gynaecol. Obstet. 1986; 24: 251-261.

10. World Bank. 2003. Investing in Maternal Health: Learning from Malaysia and Sri Lanka. Health, Nutrition, and Population Series, Human Development Network. Washington, D.C.

11. Ahman, E. and Iqbal, S. 2004. Unsafe abortion: global and regional estimates of incidence of unsafe abortion and associated mortality in 2000. World Health Organization, Geneva, 4th ed.

12. Address Unsafe Abortion. http://www.who.int/docstore/ world-health-day/en/pages1998/whd98_10.html.

13. Paxton, A., Maine, D., Freedman, L., Fry, D., and Lobis, S. The evidence for emergency obstetric care. Averting maternal death and disability. Int. J. Gynaecol. Obstet. 2005; 88: 181-193.

14. Report of the Ad Hoc Committee of the Whole of the Twenty-first Special Session of the General Assembly New York, United Nations, 1 July 1999, General Assembly document, No. A/S-21/5/Add.1.

15. Maine, D., Wardlaw, T.M., Ward, V.M., et al. Guidelines for monitoring the availability and use of obstetric services. 2nd ed. viii, 102, 1997.

16. Pearson, L. and Shoo, R. Availability and use of emergency obstetric services: Kenya, Rwanda, Southern Sudan, and Uganda. Int. J. Gynaecol. Obstet. 2005; 88: 208-215. 